\title{
Phosphoglucose Isomerase Deficiency in Escherichia coli K-12 Is Associated with Increased Spontaneous Mutation Rate
}

\author{
Elitsa Boteva1, Yordan Handzhiyski1, Maria Kotseva1, Kirill A. Datsenko², Barry L. Wanner', \\ Monika Pischetsrieder ${ }^{4}$, Roumyana Mironova ${ }^{1}$
}

\author{
${ }^{1}$ Institute of Molecular Biology Roumen Tsanev, Bulgarian Academy of Sciences, Sofia, Bulgaria \\ ${ }^{2}$ Purdue University, West Lafayette, USA \\ ${ }^{3}$ Harvard Medical School, Boston, USA \\ ${ }^{4}$ Friedrich Alexander University Erlangen-Nuremberg, Erlangen, Germany \\ Email: rumym@bio21.bas.bg
}

How to cite this paper: Boteva, E., Handzhiyski, Y., Kotseva, M., Datsenko, K.A., Wanner, B.L., Pischetsrieder, M. and Mironova, R. (2018) Phosphoglucose Isomerase Deficiency in Escherichia coli K-12 Is Associated with Increased Spontaneous Mutation Rate. Advances in Microbiology, 8, 390-405.

https://doi.org/10.4236/aim.2018.85026

Received: April 20, 2018

Accepted: May 27, 2018

Published: May 30, 2018

Copyright (c) 2018 by authors and Scientific Research Publishing Inc. This work is licensed under the Creative Commons Attribution International License (CC BY 4.0).

http://creativecommons.org/licenses/by/4.0/

\section{c) (i) Open Access}

\begin{abstract}
Phosphoglucose isomerase (PGI) is a key enzyme in early glycolysis, which catalyzes the reversible isomerization of glucose 6-phosphate $(\mathrm{G} 6 \mathrm{Ph})$ to fructose 6-phosphate. We have constructed an Escherichia coli K12 strain with a deleted $p g i$ gene $\left(\Delta p g^{i}\right)$ and shown that this strain in comparison with the parental strain 1) accumulates higher amount of $\mathrm{G} 6 \mathrm{Ph}, 2$ ) grows slowly, and 3) exhibits higher spontaneous mutation frequency to rifampicin resistance (Rif $)$, when grown on high glucose minimal medium. Intriguingly, the spontaneous mutation rate to Rif ${ }^{r}$ was inversely related to the degree of $E$. coll chromosomal DNA modification with sugar derivatives. We measured higher concentrations of Amadori products, fluorophores (360 nm excitation/440 $\mathrm{nm}$ emission) and carboxymethyl residues in the chromosomal DNA of the $E$. coli parental strain than in DNA of the isogenic $\Delta p g i$ strain. To explain this apparent paradox we hypothesized that PGI might be implicated in repair of G6Ph-derived lesions in DNA. In favor of our hypothesis, we further demonstrate that protein extract from the E. coli PGI proficient strain but not from the PGI deficient strain catalyzes the release of G6Ph from G6Ph-modified single stranded DNA oligonucleotide and from its hybrid duplex with a complementary peptide nucleic acid.
\end{abstract}

\section{Keywords}

Phosphoglucose Isomerase, Glucose 6-Phosphate, E. coli, Mutations, DNA Repair 


\section{Introduction}

Our current knowledge about the reasons underlying spontaneous mutagenesis is far from being complete. The marked advance in our understanding of how the DNA-dependent DNA polymerases work let us know that errors made during DNA replication are kept at a low frequency due to the proofreading activity of these enzymes [1] [2]. The latter, together with the post-replication mismatch repair, account for an extraordinary fidelity of DNA replication-approximately one wrong base per billion nucleotides. On the other side, bacteria mutate at a relatively high frequency of about one mutation per $10^{8}$ to $10^{6}$ cells per generation (depending on the particular gene target), which makes them a relevant model for studies on spontaneous mutagenesis.

The relative contribution of replication errors to the overall DNA mutability is a controversial issue, and it is now obvious that other, replication independent factors play an important role [3]. In the absence of an external mutagenic assault, the factors impacting spontaneous mutagenesis should be of endogenous origin. We would like to point out that the border we usually draw between ordinary cellular metabolites and mutagens is provisory. As well known, water and oxygen are life indispensable constituents, but they represent a significant source of hydrolytic and oxidative lesions in DNA [4]. In fact, $\mathrm{H}_{2} \mathrm{O}$ and $\mathrm{O}_{2}$ are the only "endogenous mutagens" studied in detail so far while the impact of other cellular metabolites on spontaneous mutagenesis has not been systematically studied.

In a previous study, we have provided the first experimental evidence that the chromosomal DNA of Escherichia coli K12 is involved in the spontaneous (non-catalyzed) chemical reaction of Maillard, known as non-enzymatic glycosylation or glycation [5]. In the early stage of these reaction carbonyl compounds, among them reducing sugars, react with primary amines including DNA to form reversible aldimines (Schiff bases). At neutral pH Schiff bases undergo a structural rearrangement to more stable ketoamines called Amadori products (APs) [6]. In the late stage of the Maillard reaction, after a series of diverse chemical transformations, APs are converted into the so called advanced glycation end products (AGEs). The latter remain covalently and irreversibly bound to the target molecules, where they may interfere with their structure and function.

In our studies, we have demonstrated that E. coli chromosomal DNA accumulates APs and AGEs under normal physiological conditions [7]. We have further shown that modification of DNA with APs and AGEs contributes to spontaneous mutagenesis in E. coli [7] [8]. In these studies, however, the nature of the endogenous sugar(s) causing damage to DNA remained largely unknown. Some authors report that hexoses that are phosphorylated at $\mathrm{C}_{6}$ are more reactive with $\mathrm{NH}_{2}$-compounds than non-phosphorylated or phosphorylated at $\mathrm{C}_{1}$ six carbon sugars [9]. Therefore, we suggested that the endogenous metabolite glucose 6-phosphate $(\mathrm{G} 6 \mathrm{Ph})$ may have higher impact on DNA glycation and spontaneous mutability than glucose. In order to explore this suggestion we 1) con- 
structed an $E$. coli strain accumulating over-physiological concentrations of $\mathrm{G} 6 \mathrm{Ph}$ by deleting the phosphoglucose isomerase gene $\left.\left(p g^{i}\right), 2\right)$ measured the amount of APs and AGEs in the chromosomal DNA of the ancestral and of the isogenic $\Delta p g i$ strain, 3) evaluated the spontaneous mutation frequency of both strains to rifampicin resistance (Rif'), and 4) tested protein extracts from both strains for ability to catalyze the removal of G6Ph-derived APs from a single stranded DNA oligonucleotide and from its hybrid duplex with a complementary peptide nucleic acid (PNA).

\section{Materials and Methods}

\subsection{E. coli Strains and Culture Media}

The E. coli strain BW28357 [rrnB3 $\Delta$ lacZ4787 hsdR514 $\triangle$ araBA-D567 $\left.\triangle r h a B A D 568 r p h^{+}\right]$was used to create the isogenic $\triangle p g i$ strain [rrnB3 $\triangle l a c Z 4787$ hsdR514 $\triangle a r a B A-D 567 \Delta r h a B A D 568 \mathrm{rph}^{+} \Delta$ pgi $\left.\mathrm{kan}^{\prime}\right]$. Bacteria were cultured in either rich Luria-Bertani (LB) or M63 minimal medium supplemented with glucose:gluconate at a mass ratio 9:1 (20\% total). For conciseness this medium is designated as M63GG throughout the text below.

\subsection{Polymerase Chain Reaction}

Chromosomal DNA of the E. coli BW28357 and the isogenic $\Delta p g i$ strains was isolated as described below (2.5.), except that the sonication step at the end was omitted. The polymerase chain reaction (PCR) was carried out in a final volume of $25 \mathrm{ul}$ containing $50 \mathrm{ng}$ template DNA, $2 \mathrm{mM} \mathrm{MgCl}_{2}, 0.2 \mathrm{mM}$ dNTPs, 20 pmol of each forward (5'CTGTGACTGGCGCTACAATC3') and reverse (5'CCGACATAACGTCGGCATTG3') primers and 1 unit Taq DNA polymerase dissolved in nuclease-free water. DNA was denatured for 5 min at $95^{\circ} \mathrm{C}$ followed by bulk DNA synthesis over 30 cycles, each composed of denaturing for $2 \mathrm{~min}$ at $95^{\circ} \mathrm{C}$, annealing for $2 \mathrm{~min}$ at $55^{\circ} \mathrm{C}$ and elongation for $2 \mathrm{~min}$ at $72^{\circ} \mathrm{C}$. One additional cycle of $5 \mathrm{~min}$ at $72^{\circ} \mathrm{C}$ was included at the end of the reaction for completion of DNA synthesis. The PCR products were analyzed by $1.2 \%$ agarose gel electrophoresis.

\subsection{Measurement of Glucose 6-Phosphate in Bacterial Lysates}

E. coli BW28357 and the isogenic $\Delta p g i$ strains were cultured in M63GG medium at $37^{\circ} \mathrm{C}$ until cultures reached an optical density of $1 \mathrm{OD}_{590}(10 \mathrm{~mm}$ cuvette path). Cells from $4 \mathrm{ml}$ cultures were collected by centrifugation for $5 \mathrm{~min}$ at 1000

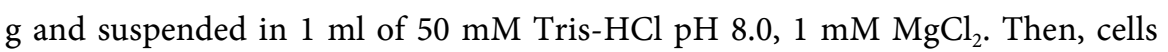
were disrupted by sonication using ultrasonic homogenizer (Model CP50, Cole-Parmer Instrument) three times for $1 \mathrm{~min}$ ( $50 \%$ duty cycle at $80 \%$ power), and cellular debris were pelleted by centrifugation at $12000 \mathrm{~g}$ for $15 \mathrm{~min}$ at $4^{\circ} \mathrm{C}$. The supernatant was supplemented with $142 \mathrm{mg}$ bentonite and incubated for 2 hours at room temperature under shaking, followed by centrifugation at 12,000 $\mathrm{g}$ for $5 \mathrm{~min}$ at $4^{\circ} \mathrm{C}$. $\mathrm{G} 6 \mathrm{Ph}$ in the resulting supernatant was measured by the re- 
duction of NADP to NADPH in the presence of yeast G6Ph-dehydorogenase (Sigma G7877) as described elsewhere [10].

\subsection{Growth Kinetics of E. coli in Rich and High Glucose Minimal Medium}

Single colonies of E. coli grown on LB agar were inoculated into $5 \mathrm{ml}$ either LB or M63GG medium and incubated overnight at $37^{\circ} \mathrm{C}$ on a New Brunswick rotary water bath shaker. Fresh $50 \mathrm{ml}$ LB or M63GG medium in 500-ml Erlenmeyer flasks were inoculated with the overnight cultures at an initial density of 0.1 $\mathrm{OD}_{590}$ and incubation was carried out at $37^{\circ} \mathrm{C}$ on the rotary shaker at $250 \mathrm{rpm}$. At $30 \mathrm{~min}$ (LB) or $60 \mathrm{~min}$ (M63GG) intervals aliquots were taken from the cultures and turbidity was measured at $590 \mathrm{~nm}$ on a Beckman Coulter DU® 650 spectrophotometer.

\subsection{Isolation of Chromosomal DNA and Quantitation of Glycation}

E. coli cells corresponding to $125 \mathrm{OD}_{590}$ grown in $\mathrm{LB}$ or M63GG medium were collected by centrifugation and suspended in $8 \mathrm{ml} 25 \mathrm{mM}$ Tris- $\mathrm{HCl} \mathrm{pH} 8,10$ mM EDTA, $0.14 \mathrm{M} \mathrm{NaCl}$ and $50 \mathrm{mM}$ glucose. Sodium dodecyl sulfate (SDS) and Proteinase $\mathrm{K}$ were added to final concentrations of $1 \%$ and $250 \mathrm{ug} / \mathrm{ml} \mathrm{respec}-$ tively, the volume was brought up to $10 \mathrm{ml}$ with distilled water, and the suspension was incubated for $40 \mathrm{~min}$ at $37^{\circ} \mathrm{C}$. After two phenol extractions DNA was ethanol precipitated and dissolved in $1 \mathrm{ml} 10 \mathrm{mM}$ Tris- $\mathrm{HCl} \mathrm{pH} \mathrm{8,1} \mathrm{mM} \mathrm{EDTA}$ (TE 10-1) containing 100 ug RNase A and 1 unit RNase T1. After 30 min incubation at $37^{\circ} \mathrm{C}$ Proteinase $\mathrm{K}$ was added at a final concentration $100 \mathrm{ug} / \mathrm{ml}$ and the incubation was continued for additional $30 \mathrm{~min}$. The samples were phenol-extracted, ethanol-precipitated and DNA was dissolved in TE 10-1 at a final concentration of $5 \mathrm{mg} / \mathrm{ml}$. DNA was sonicated to an average size below $1300 \mathrm{bp}$ and its quality was estimated by the $A_{260} / A_{280}$ spectral ratio $(2 \pm 0.1)$. Amadori products (APs), fluorescent AGEs and carboxymethyl (CM) residues in DNA were quantitated as already described [7].

\subsection{Mutational Assay}

Five $\mathrm{ml} \mathrm{LB}$ medium were inoculated with a single $E$. coli colony and incubated overnight at $37^{\circ} \mathrm{C}$ in a water bath shaker. On the next day, cells were diluted 1:1000 with LB medium and each of 10 tubes containing $5 \mathrm{ml}$ M63GG medium was inoculated with $10 \mathrm{ug}$ of the resulting dilution. Cultures were grown at $37^{\circ} \mathrm{C}$ until reaching $1 \mathrm{OD}_{590}$. Serial dilutions of these cultures were made and plated onto LB agar to count the number of viable cells. In parallel, $2 \mathrm{ml}$ of the cultures were collected by centrifugation at $1000 \mathrm{~g}$ for $5 \mathrm{~min}$ at $4^{\circ} \mathrm{C}$, suspended in $100 \mathrm{ug}$ M63GG medium and spread onto a LB agar supplemented with rifampicin at a final concentration of $100 \mathrm{ug}$. The number of exponential and stationary Rif mutants was recorded after incubation of the plates at $37^{\circ} \mathrm{C}$ for $24 \mathrm{~h}$ or $72 \mathrm{~h}$, respectively. The mutation frequencies were expressed as a number of Rif ${ }^{\mathrm{r}}$ mutants 
per $10^{8}$ viable cells and presented as a median $(\mathrm{n}=10)$. Data were processed by the Mann Whitney $U$-test [11].

\subsection{Preparation of DNA and PNA: DNA Modified with G6Ph}

In this experiment we used complementary DNA and PNA 18-mer single stranded oligonucleotides with the following sequence: DNA 5'-CTA CTA ATC AGA CTA ATA-3' and PNA 5'-TAT TAG TCT GAT TAG TAG-3'. The DNA oligonucleotide was incubated at a concentration of $100 \mathrm{uM}$ with either $0 \mathrm{mM}$, $10 \mathrm{mM}$ or $100 \mathrm{mM} \mathrm{G6Ph}$ in a volume of $100 \mathrm{ul}$ for $48 \mathrm{~h}$ at $37^{\circ} \mathrm{C}$. Non-reacted G6Ph was removed by gel-filtration on CENTRI-SPIN 10 columns (Princeton). The glycated DNA (DNA-AP) was hybridized with PNA at 1:1 molar ratio in the presence of $0.1 \mathrm{M} \mathrm{NaCl}$ under the following conditions: incubation for $10 \mathrm{~min}$ at $85^{\circ} \mathrm{C}$, gradual cooling to $37^{\circ} \mathrm{C}$ and further incubation at $37^{\circ} \mathrm{C}$ for $24 \mathrm{~h}$. DNA-AP and PNA:DNA-AP were purified from DNA fragments resulting from glycation and from the non-hybridized oligonucleotides via RP-UHPLC on Acquity UPLC BEH C18 column $(2.1 \mathrm{~mm} \times 50 \mathrm{~mm}, 1.7 \mathrm{um}, 300 \AA)$ heated to $35^{\circ} \mathrm{C}$ by applying the following $30 \mathrm{~min}$ gradient of acetonitrile $(\mathrm{ACN})$ in aqueous $10 \mathrm{mM}$ triethylammonium acetate at a flow rate $0.2 \mathrm{ml} / \mathrm{min}$ : equilibration of the column at $7 \%$ $\mathrm{ACN}$, rise in $\mathrm{ACN}$ concentration from $7 \%$ to $17 \%$ during the first $15 \mathrm{~min}$ followed by increase to $100 \% \mathrm{ACN}$ over the next $5 \mathrm{~min}$ and isocratic flow at $100 \%$ ACN for the last 10 min. Under these conditions DNA-AP and PNA: DNA-AP eluted at RT $6.3 \mathrm{~min}$ and RT $10.9 \mathrm{~min}$, respectively.

\subsection{Electrospray Ionization Mass Spectrometry of DNA-AP}

After removal of the unbound G6Ph, 2 ul of each of the incubation mixtures of the DNA oligonucleotide with G6Ph from the previous Section 2.7 were introduced into the electrospray ionization (ESI) source of the mass-spectrometer (Thermo Scientific ${ }^{\text {Tw }}$ Orbitrap Elite ${ }^{\text {tw }}$ Hybrid Ion Trap-Orbitrap) via direct infusion at a speed of the mobile phase (50\% methanol, $0.1 \%$ ammonium formate) of $5 \mathrm{ul} / \mathrm{min}$. Mass spectra were collected in the FT mode in a normal mass range from m/z 900 to m/z 1400 at a resolution of 30,000 and $50 \mathrm{~ms}$ ion injection time. The ion source was operated in a negative ion mode at $2.5 \mathrm{kV}$ ion spray voltage and a capillary temperature of $250^{\circ} \mathrm{C}$.

\subsection{Preparation of E. coli Protein Extracts and Western Blotting}

E. coli cells were cultured in $\mathrm{LB}$ medium at $37^{\circ} \mathrm{C}$ until mid-exponential phase $\left(0.5 \mathrm{OD}_{590}\right)$, collected by centrifugation for $5 \mathrm{~min}$ at $1000 \mathrm{~g}$ and washed twice with phosphate buffered saline ( $\mathrm{pH} 7.4$ ). Then, the cells were suspended in deionized water, disrupted by sonication four times for 15 seconds (50\% duty cycle at $80 \%$ power), and the cell debris were removed through centrifugation at $16,000 \mathrm{~g}$ for $30 \mathrm{~min}$ at $4^{\circ} \mathrm{C}$. The protein concentration in the resulting supernatants was determined using Sigma BCA assay kit (Prod. No. B9643). Protein extracts (25 ug per lane) were separated on 12\% SDS-polyacrylamide gel under reducing conditions $(0.7 \mathrm{M}$ beta-mercaptoethanol in protein extracts), trans- 
ferred onto PVDF-membranes and Western blotting was performed with a rabbit polyclonal anti-yeast PGI IgG (antibodies-online, Cat. No. ABIN568370). Blots were developed with an IRDye $800 \mathrm{CW}$ goat anti-rabbit IgG (Cat. No. 925-3221, LI-COR Biosciences GmbH) and visualized on an Odyssey LI-COR imaging system.

\subsection{Phosphoglucose Isomerase Activity Assay}

The assay was performed according to Bergmeyer [12] in a final volume of 0.5 $\mathrm{ml}$ containing $50 \mathrm{mM}$ Tris- $\mathrm{HCl} \mathrm{pH} \mathrm{8.0,0.67} \mathrm{mM} \mathrm{NADP,} 3.3 \mathrm{mM} \mathrm{MgCl}_{2}$ and one of the following substrates: $3.3 \mathrm{mM}$ fructose 6-phosphate, $10 \mathrm{uM}$ DNA-AP or 10 uM PNA:DNA-AP. First, 1 unit of G6Ph-dehydrogenase was added and the incubation was carried out at ambient temperature until no increase in the absorbance at $340 \mathrm{~nm}$ was observed. This step was included in order to avoid interference of any trace amounts of $\mathrm{G} 6 \mathrm{Ph}$ present in the $\mathrm{Fr} 6 \mathrm{Ph}$ preparation or in the final DNA-AP and PNA: DNA-AP samples. Then, the isomerization reaction was initiated by the addition of 8 ug $E$. coli protein extract and the increase in the absorbance at $340 \mathrm{~nm}$ was followed over time.

\section{Results}

\subsection{Inactivation of the $E$. coli pgi Gene}

The pgi gene of the E. coli strain BW28357 was deleted by one-step gene inactivation protocol with PCR products [13]. The PCR product used to replace the pgi gene is encoding kanamycin resistance $\left(\operatorname{Kan}^{\mathrm{r}}\right)$ and is shorter than the displaced chromosomal DNA region. We selected $\operatorname{Kan}^{\mathrm{r}}$ E. coli colonies and performed PCR to confirm the pgi gene deletion. With template DNA of the parental strain the chain reaction generated a DNA fragment of $1891 \mathrm{bp}$ while DNA of the knock-out strain produced a fragment of 1568 bp (Figure 1(a)) thus confirming the successful pgi gene deletion. To get an independent verification of the $p g i$ gene deletion we performed Western blotting. In this experiment we

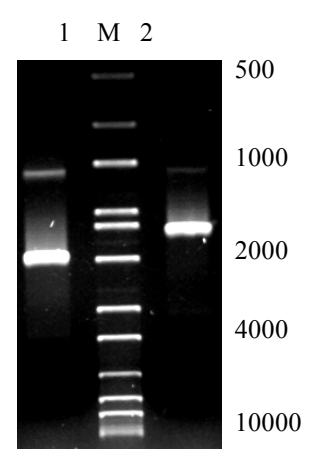

(a)

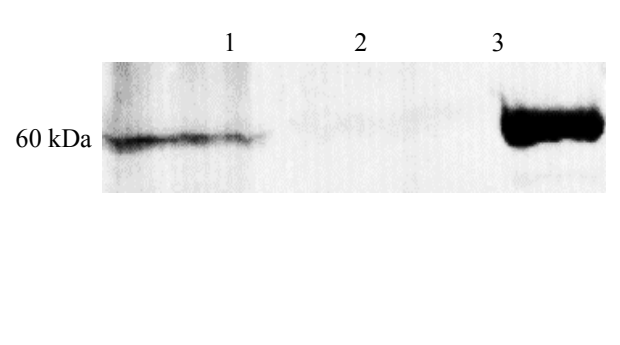

(b)

Figure 1. (a) Agarose gel electrophoresis of PCR products produced by amplification of the pgi gene region of the parental (1) and $\Delta p g i(2)$ E. coli strains, M - DNA ladder in bp; (b) Western blotting of protein extracts from the parental (1) and $\Delta p g i$ (2) E. coli strains, and of yeast PGI (Sigma P5381) with an anti-PGI antibody. 
used a polyclonal antibody raised against Saccharomyces cerevisiae PGI, which shares 59\% homology with the E. coli enzyme. As shown in Figure 1(b), positive staining with this antibody was observed only with protein extract from the parental PGI proficient strain and with yeast PGI used as a positive control. The protein extract from the $E$. coli $\Delta p g i$ strain did not react with the anti-PGI antibody.

\subsection{Growth of the E. coli Strains in LB and M63GG Medium}

PGI is converting G6Ph to fructose 6-phosphate (Fr6Ph) in the second glycolytic step. Therefore, it is expected that inactivation of the pgi gene would result in accumulation of over-physiological G6Ph concentrations in the E. coli $\Delta p g i$ strain when grown in high glucose minimal medium. To test this option, we measured the $\mathrm{G} 6 \mathrm{Ph}$ concentration in protein-deprived lysates of both the parental and $\Delta$ pgi E. coli strains grown in M63GG medium. Under these conditions the G6Ph concentration in the PGI deficient cells proved to be more than ten times higher than that in the PGI proficient cells (Figure 2(a)), which confirmed previously reported data [14] [15]. On the other hand, this result provides an independent physiological evidence for the pgi gene deletion. In next experiments we evaluated the impact of the pgi gene deletion on the growth of the PGI deficient strain. We cultured both strains in rich LB medium and in minimal M63GG medium as well. We did not observe a significant difference in the growth of both strains in LB medium (Figure 2(b)). This result is not surprising as far as in rich media alternative catabolic pathways may be activated sustaining the growth of the PGI deficient strain [16]. In M63GG medium both strains exhibited delayed growth with $\Delta p g i$ strain growing one-third as fast as the parent (Figure 2(c)). Similar inhibition of the growth of an E. coli $\Delta p g i$ strain on glucose supplemented M63 medium has been previously reported [17].

\subsection{Spontaneous Mutation Rate of the Parental and $\Delta p g i$ E. coli Strains}

In a previous study, it has been demonstrated that plasmid transformation of an

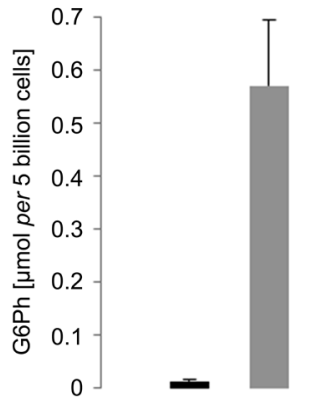

(a)

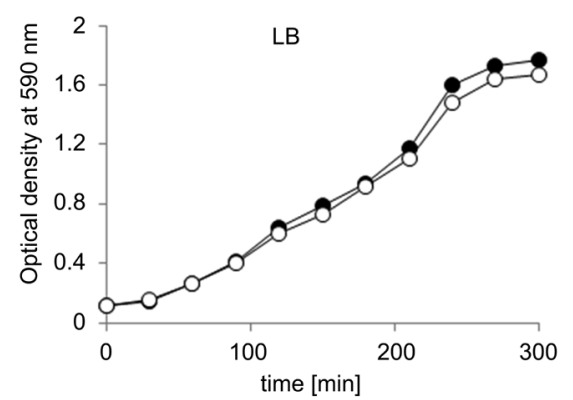

(b)

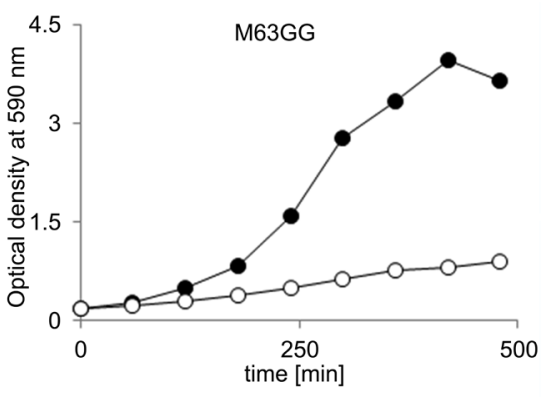

(c)

Figure 2. (a) G6Ph levels in the parental (black bar) and $\Delta$ pgi (gray bar) E. coli strains, data are means $\pm \mathrm{SD}$ of three separate cytosol's isolations. Growth of the parental (black dots) and $\Delta$ pgi (empty dots) strains in rich LB (b) and minimal M63GG medium (c). 
E. coli $\Delta$ pgi strain results in increased mutation rate of a plasmid borne marker gene [15]. In this study, we tested the impact of the pgi gene inactivation on the mutation rate of a chromosomal E. coli gene-the $r p o B$ gene encoding the beta-subunit of the RNA polymerase. Mutations in this gene result in resistance to the antibiotic rifampicin (Rif $)^{\prime}$. We recorded two types of mutations-exponential and stationary phase (adaptive) mutations. Exponential mutations arise during growth of bacteria in liquid medium in the absence of the antibiotic and are scored 24 hours after plating the cells on Rif-plates. Stationary mutations appear during growth of bacteria on the Rif-plates and are counted 72 hours after plating. We measured exponential mutation rate to Rif ${ }^{f}$ of the parental E. coli strain 19.6 mutants per $10^{8}$ viable cells versus 26.2 mutants per $10^{8}$ viable cells of the $\Delta p g i$ strain $(p<0.025, \mathrm{n}=10)$ (Figure 3(a)). For the adaptive mutations the calculated values were 9.7 mutants per $10^{8}$ viable cells for the parental strain versus 19.3 mutants per $10^{8}$ viable cells for the $\Delta p g i$ strain $(p<$ $0.005, \mathrm{n}=10$ ) (Figure $3(\mathrm{~b})$ ). These results clearly demonstrate that inactivation of the pgi gene results in increased spontaneous mutation rate to Rif ${ }^{\mathrm{r}}$ as far as both exponential and adaptive mutations appeared more frequently in the E. coli PGI deficient strain.

\subsection{Impact of pgi Gene Deletion on Glycation of Chromosomal DNA}

As demonstrated above, inactivation of the pgi gene resulted in accumulation of G6Ph in E. coli cells and in increased spontaneous mutation rate to Rif ${ }^{\mathrm{r}}$ when cells were grown in high glucose M63 minimal medium. We suggested that excess G6Ph may non-enzymatically react with DNA via the Maillard reaction (glycation) thus contributing to the increased spontaneous mutation rate to Rif ${ }^{\mathrm{r}}$ of the E. coli $\Delta p g i$ strain. To explore this suggestion, we isolated chromosomal DNA of the parental and $\Delta p g i$ E. strains and measured the amount of early glycation products (APs) (Figure 4(a)) and two types of AGEs-fluorescent AGEs

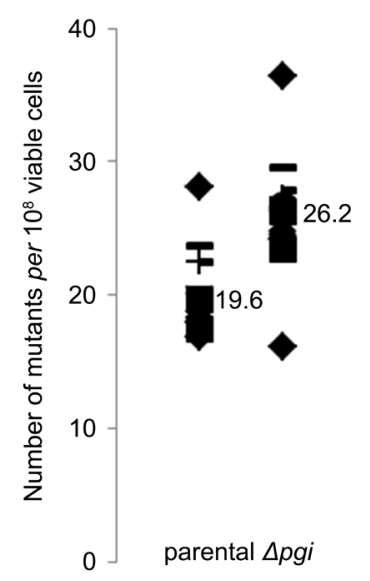

(a)

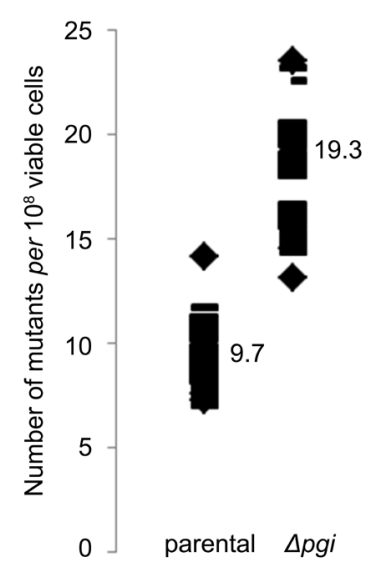

(b)

Figure 3. Rate of exponential (a) and adaptive (b) mutations to Rif ${ }^{\mathrm{r}}$ of the parental and $\Delta$ pgi E. coli strains grown on M63GG medium. 


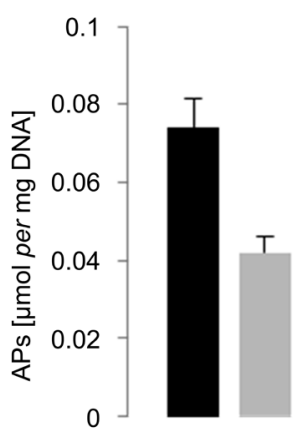

(a)

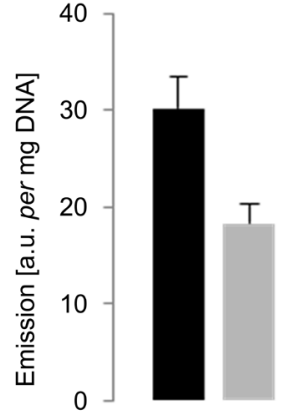

(b)

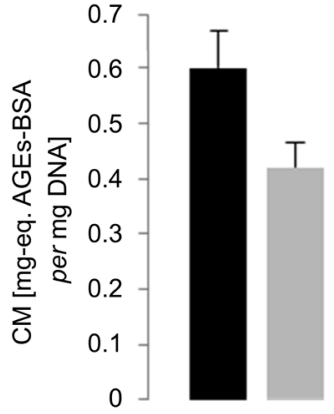

(c)

Figure 4. Amount of APs (a), fluorescent products (Ex $360 \mathrm{~nm} / \mathrm{Em} 440 \mathrm{~nm}$ ) (b) and CM-adducts (c) in chromosomal DNA of the parental (black bars) and $\Delta p g i$ (gray bars) E. coli strains; data are means \pm SD of two independent DNA isolations.

(Figure 4(b)) and carboxymethyl (CM) adducts (Figure 4(c)). The AGEs-fluorophores were detected through fluorescence spectroscopy at $440 \mathrm{~nm}$ emission wavelength upon excitation at $360 \mathrm{~nm}$. For measurement of $\mathrm{CM}$-adducts we used an antibody raised against CM-lysine, which was shown in a previous study to cross-react with glycated DNA [7]. Contrary to our expectations, we measured lower amounts of all three types of glycation adducts in the chromosomal DNA of the E. coli $\Delta p g i$ than in DNA of the parental strain (Figures $4(\mathrm{a})-(\mathrm{c})$ ).

\subsection{PGI Proficient E. coli Cells Exhibit DNA-APs Amadoriase Activity}

Amadori products (APs) are unstable intermediates of the Maillard reaction that may involve DNA in dramatic chemical rearrangements ceasing with intraand/or intermolecular crosslinking of the DNA strands and strand breaks as well [18] [19]. Given this high instability of APs-modified DNA we suggested that there should be mechanisms for repair of APs-lesions in DNA in order to prevent propagation of the DNA damage. G6Ph-derived APs in DNA represent fructose 6-phosphates, which are covalently linked to the exocyclic $\mathrm{NH}_{2}$-groups of the DNA bases G [20], A and C. Fructose 6-phosphate is a PGI substrate and the isomerization $\mathrm{G} 6 \mathrm{Ph} \leftrightarrow \mathrm{Fr} 6 \mathrm{Ph}$ is known to be easily reversible [21]. We therefore suggested that PGI might be involved in reversal of the early step of the Maillard reaction; i.e. that PGI might catalyze the isomerization of APs (DNA-fructosamine-6-phosphates) to Schiff bases

(DNA-glucosimine-6-phosphates) followed by spontaneous hydrolysis of the Schiff bases to G6Ph and free DNA. To test this hypothesis, we prepared a hybrid PNA: DNA 18-mer duplex modified with G6Ph. The DNA oligonucleotide was designed so as to contain a single guanine (see the Methods section), which is the DNA base most susceptible to glycation [19] [20] [22].

The most intense ion of the non-modified DNA oligonucleotide as analyzed by ESI-mass spectrometry (ESI-MS) was with $\mathrm{m} / \mathrm{z}$ 1088.94, which corresponds to an ion species with 5 negative charges (1088.98 calculated $\mathrm{m} / \mathrm{z}$ ) (Figure 5(a)). 


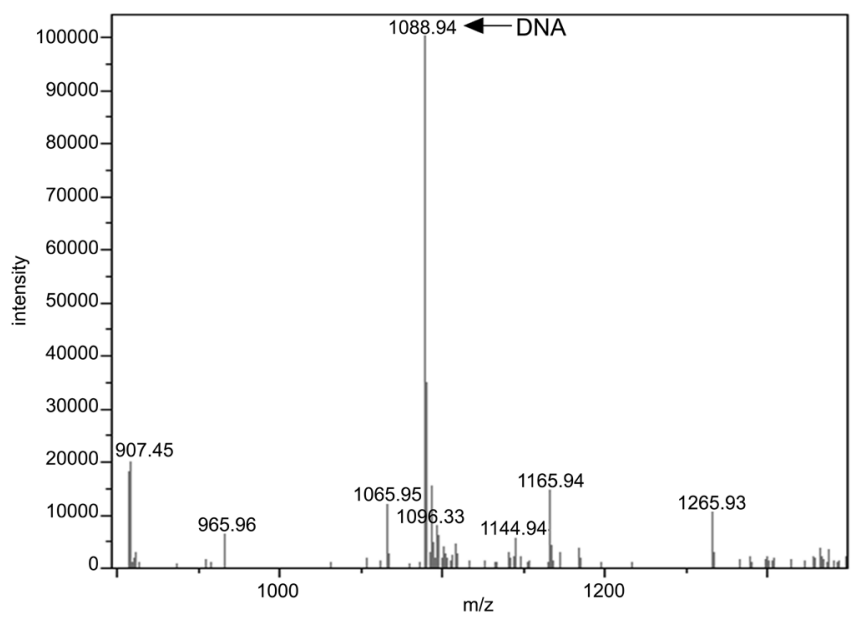

(a)

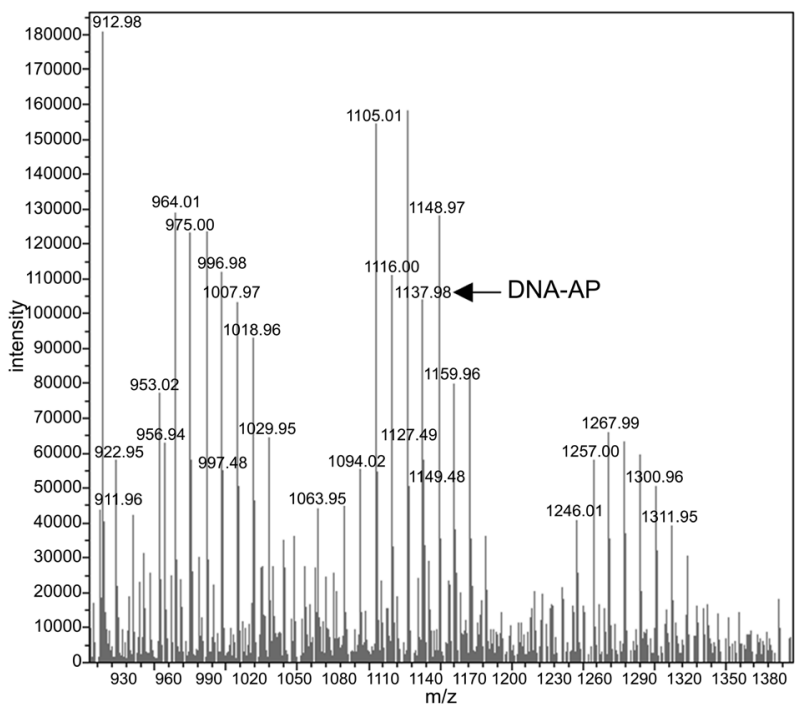

(b)

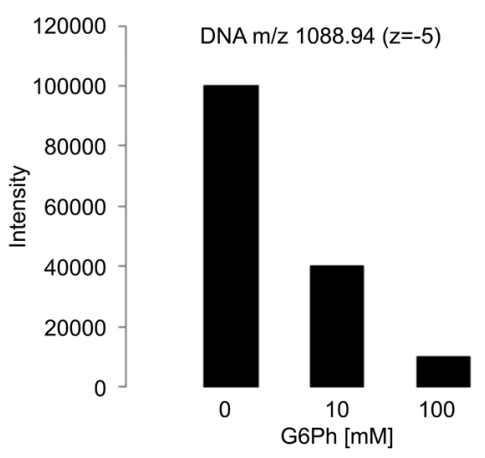

(c)

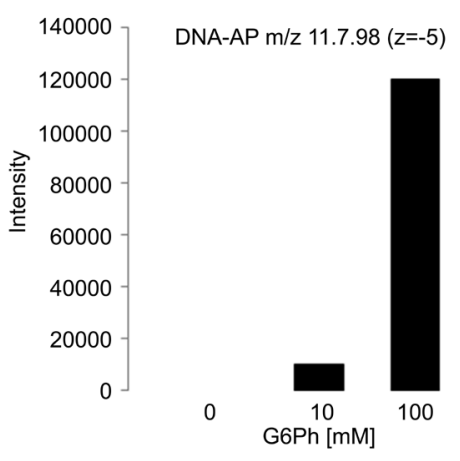

(d)

Figure 5. Mass-to-charge (m/z) spectra of the non-modified DNA oligonucleotide (a) and of the DNA oligonucleotide incubated with $100 \mathrm{mM} \mathrm{G6Ph} \mathrm{(b).} \mathrm{Depletion} \mathrm{of} \mathrm{the} \mathrm{un-}$ modified DNA oligonucleotide ( $\mathrm{m} / \mathrm{z}$ 1088.94) (c) and accumulation of the G6Ph-modified DNA oligonucleotide (m/z 1137.98) (d) with increasing G6Ph concentrations. Shown are data from a single of two independent ESI-MS experiments. Similar dynamics of the ion intensities as in (c) and (d) was observed also for $\mathrm{Na}^{+}$and $2 \mathrm{Na}^{+}$adducts of the DNA and DNA-AP ion species with $\mathrm{z}=-5$. 
We first went on modifying that DNA oligonucleotide with G6Ph, whereby we observed a concentration dependent decrease in the intensity of the ion with $\mathrm{m} / \mathrm{z}$ 1088.94 with increasing G6Ph concentrations (Figure 5(c)). In parallel, we monitored also the appearance of the ion with 5 negative charges and $\mathrm{m} / \mathrm{z} 1137.98$ of the DNA oligonucleotide modified by a single G6Ph-derived AP (1137.54 calculated $\mathrm{m} / \mathrm{z}$ ) (Figure 5(b)). Expectedly, the intensity of this ion increased with increasing G6Ph concentrations (Figure 5(d)). The many ion species in the $\mathrm{m} / \mathrm{z}$ spectrum of DNA-AP (Figure $5(\mathrm{~b})$ ) are indicative of intense DNA degradation, which clearly demonstrates the fragility of glycated DNA. In order to stabilize the DNA-AP oligonucleotide we hybridized it with a complementary PNA oligonucleotide. DNA-AP and PNA: DNA-AP were then used as substrates in a PGI activity assay coupled to the reduction of NADP to NADPH in the presence of G6Ph-dehydrogenase. We first performed a control PGI assay with Fr6Ph as a substrate. As expected, PGI activity with Fr6Ph was observed only with protein extract from the parental but not from the $\Delta$ pgi E. coli strain (Figure 6(a)). Then, the assay was conducted with DNA-AP or PNA: DNA-AP as substrates and with protein extracts from the parental or $\Delta p g i$ strains (Figure 6(b)). In favor of our suggestion we observed a release of $\mathrm{G} 6 \mathrm{Ph}$ from both $\mathrm{G} 6 \mathrm{Ph}$-modified substrates (DNA-AP and PNA: DNA-AP) only when the assay was carried out with a protein extract from the PGI proficient but not from the PGI deficient strain.

\section{Discussion}

The deletion of the E. coli pgi gene in the current study was confirmed by several independent approaches including 1) kanamycin resistance, 2) PCR amplification of a DNA fragment with the expected length, 3) lack of the PGI protein as shown by Western blotting, 4) accumulation of $\mathrm{G} 6 \mathrm{Ph}, 5)$ slowed growth on high glucose M63 medium, and 6) lack of PGI activity. Previous studies have demonstrated that incubation of a single stranded (phage) or double stranded (plasmid)

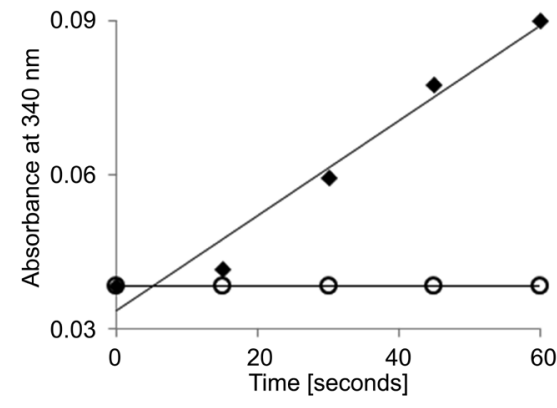

(a)

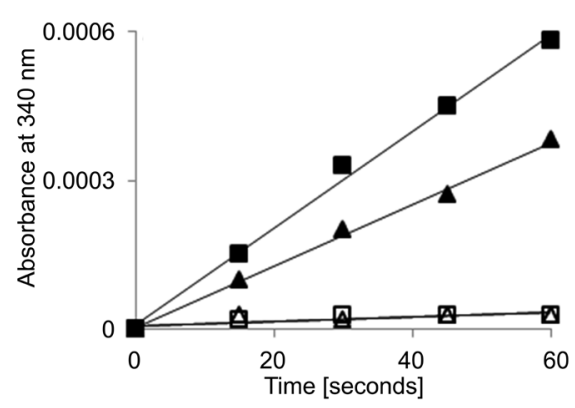

(b)

Figure 6. (a) PGI assay with $3.3 \mathrm{mM}$ Fr6Ph as a substrate and protein extract from either the PGI proficient $(\bullet)$ or PGI deficient (o) E. coli strain; (b) PGI assay with $10 \mathrm{uM}$ DNA-AP $(\boldsymbol{\Delta})$ or 10 uM PNA:DNA-AP $(\boldsymbol{\square})$ as substrates and protein extract form the PGI proficient strain. The assay was performed also with DNA-AP $(\Delta)$ or PNA: DNA-AP $(\square)$ as substrates and protein extract from the PGI deficient strain. 
DNA with G6Ph results in strand scissions in vitro, reduced efficiency of transfection/transformation into $E$. coli cells and accumulation of mutations in the vehicles in vivo [18] [23]. Similar in vivo effect was observed also when an untreated plasmid was introduced into an E. coli PGI deficient strain [15]. Here, we show that also an $E$. coli chromosomal gene $(r p o B)$ mutates at a higher frequency in the PGI deficient cells. To our surprise, however, the chromosomal DNA of this strain proved to be less modified with sugar derivatives than DNA of the isogenic parental strain. We realized that in order to shed light on this apparent paradox, we need know how glycated DNA is repaired. To date, only one study shows that translesion DNA synthesis by $E$. coli DNA polymerase IV accounts for accurate bypass of $\mathrm{N}^{2}$-(1-carboxyethyl)-2'-deoxyguanosine (CEdG) lesions in DNA in vivo [24]. However, whether and how Amadori lesions in DNA are repaired remains largely unknown at present.

Enzymes for repair of APs-modified proteins, called amadoriases, have been discovered in a broad range of organisms. The first amadoriase shown to repair glucose-modified proteins in humans was reported by E. Van Schaftingen and co-workers [25] [26]. The same group identified yet another amadoriase (FrlB) catalyzing the hydrolysis of the sugar-amine bond of $\mathrm{N}^{\mathrm{e}}$-fructoselysine-6-phosphate in E. coli [27]. Notably, the same study also found that the FrlB amodoriase shares homology with the isomerase domain of the $E$. coli glucosamine-6-phosphate synthase. Isomerase activity is intrinsic to PGI and it has been reported that the isomerization G6Ph $\leftrightarrow$ Fr6Ph catalyzed by the E. coli PGI is slightly favorable in the reverse direction $\mathrm{Fr} 6 \mathrm{Ph} \rightarrow \mathrm{G} 6 \mathrm{Ph}$ [21]. APs formed on DNA from G6Ph represent DNA-fructosamine-6-phosphates and we suggested that PGI may act as a DNA-amadoriase by catalyzing the isomerization of DNA-frucosamine-6-phosphate (AP) to DNA-glucosimine-6-phosphate (Schiff base). This would reverse the poorly reversible early step of the Maillard reaction form APs to Schiff bases. Then, DNA-glucosimine-6-phosphate is expected to spontaneously breakdown because of Schiff's base reversibility.

To test the hypothesis for DNA-amadoriase activity of PGI we went on creating a PNA: DNA hybrid duplex with a single $\mathrm{G} 6 \mathrm{Ph}$-modified residue in the DNA strand. The PNA oligonucleotide is expected to stabilize the glycated DNA strand even in case of strand scission caused by glycation. Similar model have been successfully applied for studies on the repair of thymine photodimers by photolyase [28]. Using this model and also the precursor DNA-AP oligonucleotide we have observed that protein extract from the PGI proficient strain catalyzes the release of G6Ph from both G6Ph-modified substrates. The extract from the PGI deficient strain did not exhibit such activity. These data are in favor of our suggestion that PGI might be involved in repair of G6Ph-damaged DNA. The PGI repair mechanism, we propose here, is an error-free mechanism result-

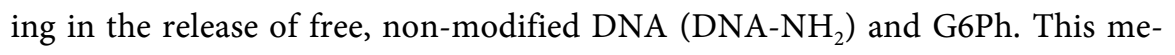
chanism is similar to that of some DNA repair enzymes that directly reverse the modification like $\mathrm{O}^{6}$-methylguanine-DNA methyltransferase [29]. 
To explain the apparent paradox of the chromosomal DNA of the PGI deficient strain being less glycated but accumulating more mutations, we suggest that under conditions of excess G6Ph and lack of PGI error-prone mechanisms for repair of APs-lesions in DNA are up-regulated. For example, inactivation of the nuclear excision repair in $E$. coli has been shown to result in decreased spontaneous mutation rate to Rif $\mathrm{f}^{\mathrm{f}}$, most likely as a result of avoiding errors that are made by DNA polymerase I during repair DNA synthesis [30]. Thus, if NER or other, error-prone mechanisms are compensating for the PGI deficiency they could promote repair of APs-lesions in DNA at the expense of enhanced mutagenesis in comparison with conditions of PGI proficiency, where PGI would account for error-free DNA repair and consequently for a lower mutation rate. The proposed DNA repair activity of the glycolytic enzyme PGI, if confirmed in further studies, will not be a precedent. Another glycolytic enzyme, the human glyceraldehyde-3-phosphate dehydrogenase, for example, has been shown to function as an uracil DNA glycosylase [31], and almost all glycolytic enzymes in eukaryotes, among them PGI, have been found to moonlight in the nucleus [32]. Why PGI "travels" to the nucleus is currently unknown. Our study points to at least one rationale for nuclear localization of PGI and opens the avenue for further exploration of the possible involvement of PGI in repair of G6Ph-damaged DNA.

\section{Conclusion}

In this study, we have shown that deletion of the pgi gene in Escherichia coli $\mathrm{K}-12$ results in accumulation of $\mathrm{G} 6 \mathrm{Ph}$, delayed growth, and increased spontaneous mutation rate to Rif ${ }^{r}$ when cells are grown in high glucose minimal medium. Contrary to our expectation, the chromosomal DNA of the E. coli PGI deficient strain proved to be less modified with carbonyl derivatives as compared to the chromosomal DNA of the PGI proficient strain. We further found that protein extract from the PGI proficient but not from the PGI deficient strain catalyzes the release of $\mathrm{G} 6 \mathrm{Ph}$ from $\mathrm{G} 6 \mathrm{Ph}$-modified single stranded DNA oligonucleotide and from its hybrid duplex with a complementary PNA. Our study also demonstrates the high fragility of G6Ph-modified DNA and points to the possible involvement of PGI in repair of G6Ph-derived lesions in DNA.

\section{Acknowledgements}

This work has been supported by the National Science Fund of the Republic of Bulgaria by Contract No. DN01/5/16.12.2016, and by the Bulgarian Academy of Sciences by Contract No. DFNP 79-A1/28.04.2016

\section{References}

[1] Bruce, A. (2017) Molecular Biology of the Cell. 6th Edition, Garland Science, New York.

[2] Fijalkowska, I.J., Schaaper, R.M. and Jonczyk, P. (2012) DNA Replication Fidelity in Escherichia coli: A Multi-DNA Polymerase Affair. FEMS Microbiology Reviews, 36 
1105-1121. https://doi.org/10.1111/j.1574-6976.2012.00338.x

[3] Whittle, C.A. and Johnston, M.O. (2006) Moving Forward in Determining the Causes of Mutations: the Features of Plants that Make them Suitable for Assessing the Impact of Environmental Factors and Cell Age. Journal of Experimental Botany, 57, 1847-1855. https://doi.org/10.1093/jxb/erj155

[4] Klungland, A. and Bjelland, S. (2007) Oxidative Damage to Purines in DNA: Role of Mammalian Ogg1. DNA Repair (Amsterdam), 6, 481-488. https://doi.org/10.1016/j.dnarep.2006.10.012

[5] Maillard, L.C. (1912) Action des Acides Amines sur les Sucres: Formation des Melanoidines par voie Methodique. Comptes rendus de l'Académie des Sciences (Paris), 154, 66-68.

[6] Amadori, M. (1925) Prodotti di Condensazione tra il Glucosio e la para Fenetidina. Parte I. Atti della Accademia nazionale dei Lincei, Rome, Rendiconti, 2, 337-342.

[7] Mironova, R., Niwa, T., Handzhiyski, Y., Sredovska, A. and Ivanov, I. (2005) Evidence for Non-Enzymatic Glycosylation of Escherichia coli Chromosomal DNA. Molecular Microbiology, 55, 1801-1811. https://doi.org/10.1111/j.1365-2958.2005.04504.x

[8] Mironova, R., Handzhiyski, Y., Niwa, T., Berzal-Herranz, A., Datsenko, K.A., Wanner, B.L. and Ivanov I. (2008) Maillard Reaction and Spontaneous Mutagenesis in Escherichia coli. In: Knutsen, D.W. and Bruns, S.S., Eds., Bacterial DNA, DNA Polymerase and DNA Helcases. Nova Science Publishers, Inc., New York, 51-89.

[9] Levi, B. and Werman, M.J. (2001) Fructose Triggers DNA Modification and Damage in an Escherichia coli Plasmid. The Journal of Nutritional Biochemistry, 12, 235-241. https://doi.org/10.1016/S0955-2863(00)00158-3

[10] Zhu, A., Romero, R. and Petty, H.R. (2011) An Enzymatic Colorimetric Assay for Glucose-6-Phosphate. Analytical Biochemistry, 419, 266-270.

https://doi.org/10.1016/j.ab.2011.08.037

[11] Mann, H.B. and Whitney, D.R. (1947) On a Test of whether One of Two Random Variables Is Stochastically Larger than the Other. Annals of Mathematical Statistics, 18, 50-60. https://doi.org/10.1214/aoms/1177730491

[12] Bergmeyer, H.U., Gawehn, K. and Grassl, M. (1974) Methods of Enzymatic Analysis. 2nd Edition, Academic Press, New York.

[13] Datsenko, K.A. and Wanner, B.L. (2000) One-Step Inactivation of Chromosomal Genes in Escherichia coli K-12 Using PCR Products. Proceedings of the National Academy of Sciences of the United States of America, 12, 6640-6645.

https://doi.org/10.1073/pnas.120163297

[14] Fraenkel, D.G. (1968) The Accumulation of Glucose 6-Phosphate from Glucose and its Effect in an Escherichia coli Mutant Lacking Phosphoglucose Isomerase and Glucose 6-Phosphate Dehydrogenase. Journal of Biological Chemistry, 243, 6451-6457.

[15] Lee, A.T. and Cerami, A. (1987) Elevated Glucose 6-Phosphate Levels Are Associated with Plasmid Mutations in Vivo. Proceedings of the National Academy of Sciences of the United States of America, 84, 8311-8314. https://doi.org/10.1073/pnas.84.23.8311

[16] Hua, Q., Yang, C., Baba, T., Mori, H. and Shimizu, K. (2003) Responses of the Central Metabolism in Escherichia coli to Phosphoglucose Isomerase and Glucose-6-Phosphate Dehydrogenase Knockouts. Journal of Bacteriology, 185, 7053-7067. https://doi.org/10.1128/JB.185.24.7053-7067.2003 
[17] Fraenkel, D.G. and Levisohn, S.R. (1967) Glucose and Gluconate Metabolism in an Escherichia coli Mutant Lacking Phosphoglucose Isomerase. Journal of Bacteriology, 93, 1571-1578.

[18] Bucala, R., Model, P. and Cerami, A. (1984) Modification of DNA by Reducing Sugars: A Possible Mechanism for Nucleic Acid Aging and Age-Related Dysfunction in Gene Expression. Proceedings of the National Academy of Sciences of the United States of America, 81, 105-109. https://doi.org/10.1073/pnas.81.1.105

[19] Ashraf, J.M., Arif, B., Dixit, K. and Moinuddin, A.K. (2012) Physicochemical Analysis of Structural Changes in DNA Modified with Glucose. International Journal of Biological Macromolecules, 51, 604-611. https://doi.org/10.1016/j.ijbiomac.2012.06.013

[20] Dutta, U., Cohenford, M.A., Guha, M. and Dain, J.A. (2006) In Vitro Nonenzymatic Glycation of DNA Nucleobases: an Evaluation of Advanced Glycation End Products under Alkaline pH. Analytical and Bioanalytical Chemistry, 386, 1633-1640. https://doi.org/10.1007/s00216-006-0753-2

[21] Gao, H., Chen, Y. and Leary, J.A. (2005) Kinetic Measurements of Phosphoglucose Isomerase and Phosphomannose Isomerase by Direct Analysis of Phosphorylated Aldose-Ketose Isomers Using Tandem Mass Spectrometry. International Journal of Mass Spectrometry, 240, 291-299. https://doi.org/10.1016/j.ijms.2004.09.017

[22] Dutta, U., Cohenford, M.A. and Dain, J.A. (2005) Nonenzymatic Glycation of DNA Nucleosides with Reducing Sugars. Analytical Biochemistry, 345, 171-180. https://doi.org/10.1016/j.ab.2005.07.034

[23] Bucala, R., Model, P., Russel, M. and Cerami, A. (1985) Modification of DNA by Glucose 6-Phosphate Induces DNA Rearrangements in an Escherichia coli Plasmid. Proceedings of the National Academy of Sciences of the United States of America, 82, 8439-8442. https://doi.org/10.1073/pnas.82.24.8439

[24] Yuan, B., Cao, H., Jiang, Y., Hong, H. and Wang, Y. (2008) Efficient and Accurate Bypass of $\mathrm{N}^{2}$-(1-carboxyethyl)-2'-deoxyguanosine by DinB DNA Polymerase in Vitro and in Vivo. Proceedings of the National Academy of Sciences of the United States of America, 105, 8679-8684. https://doi.org/10.1073/pnas.0711546105

[25] Delpierre, G., Rider, M.H., Collard, F., Stroobant, V., Vanstapel, F., Santos, H. and Van Schaftingen, E. (2000) Identification, Cloning, and Heterologous Expression of a Mammalian Rructosamine-3-Kinase. Diabetes, 49, 1627-1634. https://doi.org/10.2337/diabetes.49.10.1627

[26] Delpierre, G., Collard, F., Fortpied, J. and Van Schaftingen, E. (2002) Fructosamine 3-Kinase Is Involved in an Intracellular Deglycation Pathway in Human Erythrocytes. Biochemical Journal, 365, 801-808. https://doi.org/10.1042/bj20020325

[27] Wiame, E., Delpierre, G., Collard, F. and Van Schaftingen, E. (2002) Identification of a Pathway for the Utilization of the Amadori Product Fructoselysine in Escherichia coli. Journal of Biological Chemistry, 277, 42523-42529. https://doi.org/10.1074/jbc.M200863200

[28] Ramaiah, D., Kan, Y., Koch, T., Orum, H. and Schuster, G.B. (1998) Enzymatic Reaction with Unnatural Substrates: DNA Photolyase (Escherichia coli) Recognizes and Reverses Thymine [2+2] Dimers in the DNA Strand of a DNA/PNA Hybrid Duplex. Proceedings of the National Academy of Sciences of the United States of America, 95, 12902-12905. https://doi.org/10.1073/pnas.95.22.12902

[29] Duguid, E.M., Mishina, Y. and He, C. (2003) How Do DNA Repair Proteins Locate Potential Base Lesions? A Chemical Crosslinking Method to Investigate $\mathrm{O}^{6}$-Alkylguanine-DNA Alkyltransferases. Chemistry \& Biology, 10, 827-835. https://doi.org/10.1016/j.chembiol.2003.08.007 
[30] Hasegawa, K., Yoshiyama, K. and Maki, H. (2008) Spontaneous Mutagenesis Associated with Nucleotide Excision Repair in Escherichia coli. Genes to Cells, 13, 459-469. https://doi.org/10.1111/j.1365-2443.2008.01185.x

[31] Meyer-Siegler, K., Mauro, D.J., Seal, G., Wurzer, J., deRiel, J.K. and Sirover, M.A. (1991) A Human Nuclear Uracil DNA Glycosylase Is the 37-kDa Subunit of Glyceraldehyde-3-Phosphate Dehydrogenase. Proceedings of the National Academy of Sciences of the United States of America, 88, 8460-8464.

https://doi.org/10.1073/pnas.88.19.8460

[32] Boukouris, A.E., Zervopoulos, S.D. and Michelakis, E.D. (2016) Metabolic Enzymes Moonlighting in the Nucleus: Metabolic Regulation of Gene Transcription. Trends in Biochemical Sciences, 41, 712-730. https://doi.org/10.1016/j.tibs.2016.05.013 